\title{
Requirement for ubiquinone downstream of cytochrome(s) $b$ in the oxygen-terminated respiratory chains of Escherichia coli K-12 revealed using a null mutant allele of ubiCA
}

\author{
Britta Søballe $\mathrm{e}^{1,2}$ and Robert K. Poole $\mathrm{e}^{2}$ \\ Author for correspondence: Robert K. Poole. Tel: +44 1142224447 . Fax: +44 1142728697. \\ e-mail: r.poole@sheffield.ac.uk
}

1 Division of Life Sciences, King's College London, Campden Hill Road, London W8 7AH, UK

2 Department of Molecular Biology and

Biotechnology, Krebs Institute for Biomolecular Research, The University of Sheffield, Firth Court, Western Bank,

Sheffield S10 2TN, UK

\begin{abstract}
An Escherichia coli knockout ubicA mutant has been constructed using a gene replacement method and verified using both Southern hybridization and PCR. The mutant, which was unable to synthesize ubiquinone (Q), showed severely diminished growth yields aerobically but not anaerobically with either nitrate or fumarate as terminal electron acceptors. Low oxygen uptake rates were demonstrated in membrane preparations using either NADH or lactate as substrates. However, these rates were greatly stimulated by the addition of ubiquinone-1 (Q-1). The rate of electron transfer to those oxidase components observable by photodissociation of their CO complexes was studied at sub-zero temperatures. In the ubiCA mutant, the reduced form of haemoproteins predominantly cytochrome $b_{595}$ - was reoxidized significantly faster in the presence of oxygen than in a Ubi+ strain, indicating the absence of $Q$ as electron donor. Continuous multiple-wavelength recordings of the oxidoreduction state of cytochrome(s) $b$ during steady-state respiration showed greater reduction in membranes from the ubiCA mutant than in wildtype membranes. A scheme for the respiratory electron-transfer chain in $E$. coli is proposed, in which $Q$ functions downstream of cytochrome(s) $b$.
\end{abstract}

Keywords: aerobic respiration, cytochrome $b$, ubiquinone mutants, Escherichia coli

\section{INTRODUCTION}

Quinones are key constituents of the membrane-bound respiratory electron transfer chains in both prokaryotes and eukaryotes. These lipid components, containing isoprenoid side chains of various lengths, can be divided into two major structural groups, benzoquinones and naphthoquinones. The facultatively anaerobic bacterium Escherichia coli is capable of synthesizing octaprenyl quinones of both types, i.e. a benzoquinone, ubiquinone-8 (Q-8), and two types of naphthoquinone, menaquinone-8 (MQ-8) and demethylmenaquinone (DMQ) (Meganathan, 1996). The ratio of the quinones is variable and dependent on the growth conditions. Thus, in aerobically grown E. coli, Q is dominant in a 4to 20-fold excess over MQ (Ingledew \& Poole, 1984;

Abbreviations: $Q$, ubiquinone; $Q-n$, ubiquinone- $n$ (where $n$ is the number of isoprenoid units in the polyprenyl side chain); MQ, menaquinone; MQ8, menaquinone-8; DMQ, demethylmenaquinone; $\mathrm{Km}$, kanamycin; $\mathrm{Cm}$, chloramphenicol.
Gennis \& Stewart, 1996). Mutants that lack either Q or $M Q$ can grow under appropriate conditions, but the $i s p B$ gene, which is needed for synthesis of the side chain, appears to be essential for E. coli (Okada et al., 1997).

The flexibility of the respiratory system in response to environmental changes is due in part to the mobile quinone pool. All of the low-potential segments (dehydrogenases) are quinone reductases, whereas all the high-potential terminal oxidases become reduced by quinols. The functions of the different quinones have been studied by biochemical and physical characterization of mutants defective in quinone biosynthesis. A major problem in interpretation of some of these studies is that the mutants used have generally been isolated after chemical mutagenesis (see, for example, Gibson, 1973; Nakahigashi et al., 1992) and are unstable or leaky. Nevertheless, a consensus view is that Q-8 is used for oxygen respiration, both $Q$ and $M Q$ are involved in nitrate respiration (Wallace \& Young, 1977), while MQ and DMQ are used for anaerobic respiration 
with fumarate and other acceptors except nitrate. The dehydrogenases also show a degree of quinone specificity: thus, only $Q$ appears to function in succinate oxidation. This specificity is reflected in part by the midpoint potentials of the respiratory components involved; the value reported for the menaquinone/ menaquinol couple $\left(E_{\mathrm{m}, 7}-74 \mathrm{mV}\right)$ is lower than for the ubiquinone $(\mathrm{Q}) /$ ubiquinol $\left(\mathrm{QH}_{2}\right)$ couple $\left(E_{\mathrm{m}, 7}\right.$ +113 mV) (Gennis \& Stewart, 1996).

The biosynthetic pathway for $Q$ was determined (Gibson, 1973) by identification of intermediates accumulated by Q-deficient (ubi) mutant strains obtained after chemical mutagenesis. The first step of the biosynthetic pathway is the conversion of chorismate to 4-hydroxybenzoate by chorismate lyase. In the following step, 3-octaprenyl-4-hydroxybenzoate is produced by 4hydroxybenzoate octaprenyltransferase. These enzymes are encoded by $u b i C$ and $u b i A$ respectively, and catalyse steps in $\mathrm{Q}$ biosynthesis that are probably rate-limiting in biosynthesis. The UbiA protein was found to be of special importance, together with the IspB protein, for the overproduction of $\mathrm{Q}$ by genetic engineering ( $\mathrm{Zhu}$ et al., 1995). We have cloned and sequenced three $u b i$ genes: the ubiCA operon $(91.5$ to $91.6 \mathrm{~min}$; Wu et al., 1993), and ubiG (50.3 min; Wu et al., 1992). The UbiG protein catalyses the $S$-adenosylmethionine-dependent terminal $O$-methylation step and also the prior $O$ methylation leading to 2-octaprenyl-6-methoxyphenol (Hsu et al., 1996). The ubiX (Nonet et al., 1987; for comments see Meganathan, 1996), ubiB (Spyrou et al., 1991; Daniels et al., 1992), ubiH (Nakahigashi et al., 1992) and $u b i E$ (Lee et al., 1997) genes have also been identified, cloned and sequenced. The Q biosynthetic pathway is strikingly similar in E. coli and in eukaryotes (Hsu et al., 1996).

Despite intensive studies on the structure and function of the respiratory chain components in E. coli, there is still considerable uncertainty regarding the number of sites in the respiratory chains where $\mathrm{Q}$ acts and the roles of the various $b$-type cytochromes. To date, chemically produced mutants have been used to explore this problem. Cox et al. (1970) used a ubiB mutant and measured the proportion of respiratory carriers (flavins, cytochromes $b$ and $d$ ) that were reduced in the aerobic steady state accompanying NADH oxidation. The reduction level of cytochrome(s) $b$ was higher in the $u b i$ mutant than in the wild-type, suggesting a pool of cytochrome upstream of Q. Such an organization was supported by the experiments of Downie \& Cox (1978) and Kita \& Anraku (1981). Wallace \& Young (1977) demonstrated quinone specificity in the reactivation of oxygen respiration in a $u b i A m e n A$ mutant using various substrates. This observation led to the proposal of a $Q$ site between the respective dehydrogenases and one or more $b$-type cytochromes, but their findings did not preclude two sites for quinone function. However, the two-quinone pool hypothesis has been contradicted by Au et al. (1984). They re-examined the role of quinones in the cytochrome o-terminated branch of the E. coli respiratory chain (in a $\mathrm{Cyd}^{-}$background) and reported a lower level of cytochrome $b$ reduction during steadystate respiration of a $u b i A c y d$ mutant.

The objective of the present work was to re-examine the role of $\mathrm{Q}$ in $E$. coli using a null mutant constructed by deletion-insertion mutagenesis of the $u b i C A$ genes. This mutant was used to explore the role of $\mathrm{Q}$ in aerobic and anaerobic growth and respiration. Using continuous multi-wavelength spectrophotometric techniques it was possible to confirm previous claims for enhanced cytochrome $b$ reduction during respiration of a $u b i$ mutant, supporting a model in which electron transfer from dehydrogenases to oxidases requires two functionally discrete quinone pools, i.e. before and after cytochrome(s) $b$.

\section{METHODS}

Bacterial strains and plasmids. Bacterial strains, which were all derivatives of $E$. coli $\mathrm{K}-12$, and plasmids used are described in Table 1 .

Growth media and conditions. LB liquid medium and LB plates were prepared as described by Maniatis et al. (1982). For membrane preparations, cultures of the $u b i$ mutant and wild-type strains were grown with shaking (200 r.p.m.) in LB medium supplemented with $0.5 \%$ glucose, in 21 Erlenmeyer flasks containing $500 \mathrm{ml}$ medium. Anaerobic cultures were grown in Luria/glycerol/nitrate (LGN) medium, containing $\left(\mathrm{g} \mathrm{l}^{-1}\right)$ tryptone (10), yeast extract (5), $\mathrm{NaCl}(0.5)$, glycerol (5) and $\mathrm{NaNO}_{3}(10)$, adjusted to an initial pH of $7 \cdot 0$ with $\mathrm{NaOH}$. For solid medium, $15 \mathrm{~g}$ agar was added. Anaerobic cultures were grown overnight in Schott screw-capped bottles, with the caps left loose, in an anaerobic jar having an atmosphere generated using a GasPak (Oxoid). Antibiotics were added to the following final concentrations: chloramphenicol $(\mathrm{Cm})$ $20 \mu \mathrm{g} \mathrm{ml}^{-1}$ and kanamycin $(\mathrm{Km}) 50 \mu \mathrm{g} \mathrm{m}^{-1}$.

Succinate minimal medium for aerobic growth was as described by Poole et al. (1989). Nitrate/fumarate/glycerol minimal medium is a defined medium for anaerobic growth described by Wu et al. (1993). Aerobic cultures were grown with vigorous shaking (200 r.p.m.). Anaerobic cultures were grown in sealed test tubes and supplemented with either sodium nitrate (up to $5 \mathrm{mM}$ ) or sodium fumarate (up to $5 \mathrm{mM}$ ) as electron acceptors.

For growth yield experiments, cells were grown in $10 \mathrm{ml}$ volumes of MOPS medium (Stewart \& Parales, 1988), supplemented with limiting concentrations $(3-5 \mathrm{mM})$ of the substrates described in Results. The inocula used $(1 \%)$ were from overnight cultures grown with $5 \mathrm{mM}$ glucose such that cultures were carbon-depleted when used. Aerobic cultures were shaken ( 200 r.p.m.) in $250 \mathrm{ml}$ conical flasks with matched glass tubes of Klett dimensions as a side arm. For anaerobic growth, cells were grown in screw-capped glass tubes (Stewart \& Parales, 1988), filled to the brim with MOPS medium supplemented with $0.3 \%$ Casamino acids (Difco) and containing two glass balls (approx. $1 \mathrm{~mm}$ diameter) to aid resuspension of cells that had settled during static culture. Turbidity was measured with a Klett colorimeter (Manostat) fitted with a red filter. Culture turbidities were routinely measured up to $48 \mathrm{~h}$ after inoculation or when two successive readings were similar.

DNA manipulations. These were carried out using standard procedures (Maniatis et al., 1982). DNA was recovered from agarose gels using a GeneClean Kit (Biolol). Transformation was performed using $\mathrm{CaCl}_{2}$-treated competent cells. Chromo- 
Table 1. Strains and plasmids

\begin{tabular}{|c|c|c|}
\hline Strain or plasmid & Relevant characteristics & Reference or source \\
\hline \multicolumn{3}{|l|}{ E. coli } \\
\hline MG1655 & $\mathrm{F}^{-}$, referred to as wild-type & $\begin{array}{l}\text { H. D. Williams (Imperial } \\
\text { College London, UK) }\end{array}$ \\
\hline RKP4151 & $\mathrm{Cm}^{\mathrm{R}} \mathrm{Km}^{\mathrm{R}}$, cointegration of $\mathrm{pRKP} 952$ into chromosome of MG1655 & This work \\
\hline RKP4152 & $\mathrm{Km}^{\mathrm{R}}, \Delta u b i C A:: \mathrm{Km}^{\mathrm{R}}$ & This work \\
\hline XL-1 Blue & recA1 & Stratagene \\
\hline \multicolumn{3}{|l|}{ Plasmids } \\
\hline pBRP23 & $2.6 \mathrm{~kb}$ ClaI-PvuII fragment $\left(u b i C A^{+}\right)$cloned in pBluescript II SK( + ) & Wu et al. (1993) \\
\hline pMAK705 & $\mathrm{Cm}^{\mathrm{R}}, \operatorname{lac} Z \operatorname{rep}(\mathrm{ts})$ & Hamilton et al. (1989) \\
\hline pRKP951 & $\begin{array}{l}\text { Ap }^{\mathrm{R}} \mathrm{Km}^{\mathrm{R}} \text { cartridge replacing } 0.6 \mathrm{~kb} \text { Bam HI fragment of } u b i C A \text {, cloned in } \\
\text { pBluescript II SK(+) }\end{array}$ & This work \\
\hline pRKP952 & $\mathrm{Cm}^{\mathrm{R}}$, lacZ rep(ts), $2 \cdot 8 \mathrm{~kb} u b i C A:: \mathrm{Km}^{\mathrm{R}}$ fragment in pMAK705 & This work \\
\hline
\end{tabular}

somal DNA was purified by ultracentrifugation in $\mathrm{CsCl} /$ ethidium bromide gradients. For Southern hybridization, EcoRI-digested DNA was transferred from a $0.8 \%$ agarose gel to a Hybond-N + membrane. Three different single-stranded probes were used: the $\mathrm{Km}^{\mathrm{R}}$ gene excised with $S m a \mathrm{I}$ from plasmid pUC4-KIXX (Pharmacia), the wild-type $0.63 \mathrm{~kb}$ PCR product shown in Fig. 1, and finally the NbeI-BclI $517 \mathrm{bp}$ fragment present in $u b i A$ in both wild-type and mutant strains. The labelling of the probes and the detection of hybridization were performed using the Enhanced Chemiluminescent Detection System (ECL; Amersham).

Construction of a ubi mutant. The method for generating mutations in the $E$. coli chromosome by allele exchange described by Hamilton et al. (1989) was used. This relies on the use of a temperature-sensitive recombinant plasmid pMAK 705 carrying a mutagenized copy of the gene in question. The recipient strain is transformed with plasmid DNA and cells are selected at $42{ }^{\circ} \mathrm{C}$ for integration of the plasmid into the chromosome. Subsequent growth of the cointegrate at $30^{\circ} \mathrm{C}$ results in a second crossover, regeneration of the plasmid, and replacement of the chromosomal copy of the mutant allele. The ubiCA operon in pBRP23 (Wu et al., 1993) was inactivated by insertion of the $1.2 \mathrm{~kb} \mathrm{Km}^{\mathrm{R}} \mathrm{Tn} 5$ cartridge from pUC4-KIXX (Pharmacia). This cartridge replaced a 587 bp $B a m \mathrm{HI}$ fragment extending from the $3^{\prime}$ end of $u b i C$ into the $5^{\prime}$ end of $u b i A$. Plasmid pRP952 was generated by subcloning the $u b i C A:: \mathrm{Km}^{\mathrm{R}}$ fragment into vector pMAK 705 , which contains a thermosensitive replicon derived from a mutant isolate of pSCl01 (Hamilton et al., 1989). Thereafter, the method described by Hamilton et al. (1989) was used.

Polymerase chain reaction. PCR reactions were performed in an Omnigene Thermocycler (Hybaid). Two oligonucleotide primers were designed: the forward primer $\left(5^{\prime}\right.$ GTAAAGAGATCCCTGCCCT $3^{\prime}$ ) was complementary to a region immediately upstream of the $\mathrm{BamHI}$ site in $u b i C$, whereas the reverse primer $\left(5^{\prime}\right.$ CCCGCGACAAACACCGCCA $\left.3^{\prime}\right)$ was complementary to a region immediately downstream of the $B a m \mathrm{HI}$ site in $u b i A$ (Fig. 1). The PCR mixture contained $50 \mathrm{ng}$ genomic DNA, $7 \mathrm{pmol}$ of each primer, $0.2 \mathrm{mM}$ dNTP, $2 \mathrm{mM}$ DTT, 1 unit Taq polymerase and Taq buffer with $1 \mathrm{mM}$ $\mathrm{MgCl}_{2}$. The PCR programme consisted of 30 cycles: denaturation at $94{ }^{\circ} \mathrm{C}$ for $1 \mathrm{~min}$, primer annealing at $62^{\circ} \mathrm{C}$ and elongation at $72^{\circ} \mathrm{C}$ for $3 \mathrm{~min}$. In the first cycle, the template DNA became single-stranded, and in the last step a prolonged elongation time $(10 \mathrm{~min})$ permitted the formation of a large amount of complete double-stranded DNA. The resulting products were visualized on a $1 \%$ agarose gel.

Preparation of membranes. One litre of culture was harvested at $10000 \mathrm{~g}$ and the cells washed in $50 \mathrm{mM}$ Tris/ $\mathrm{HCl}$ buffer, $\mathrm{pH} 7 \cdot 0$. The cells were then resuspended in buffer that contained $0.1 \mathrm{M}$ TES, $20 \mathrm{mM}$ magnesium acetate, $0.25 \mathrm{M}$ sucrose and $0.25 \mathrm{mM}$ EGTA. A small quantity of DNaseI and $1 \mathrm{mM}$ PMSF (from a $0.25 \mathrm{M}$ stock in ethanol) were added to the cells, which were frozen overnight at $-20^{\circ} \mathrm{C}$. Frozen cells were disrupted by sonication for five $1 \mathrm{~min}$ periods, with $1 \mathrm{~min}$ chilling between treatments. Cell debris and unbroken cells were removed by centrifugation at $10000 \mathrm{~g}$ for $20 \mathrm{~min}$. The supernatant was centrifuged at $120000 \mathrm{~g}$ for $1.5 \mathrm{~h}$. The membrane pellet was resuspended in buffer $(50 \mathrm{mM}$ TES, $5 \mathrm{mM}$ EDTA) and homogenized. The membranes were again pelleted by centrifugation and finally resuspended and homogenized in $5 \mathrm{ml}$ of the same buffer. The membranes were stored at $-70^{\circ} \mathrm{C}$ until use. Protein concentrations were determined by the method of Markwell et al. (1978).

Oxygen consumption measurements. Oxygen consumption was measured using an inverted Clark-type oxygen electrode (Rank; Poole, 1977) polarized at $0.65 \mathrm{~V}$. Temperature was maintained with a water jacket around the chamber, which was fitted with a close-fitting deep plug, having a $<1 \mathrm{~mm}$ diameter hole for injecting reactants with minimum oxygen penetration. Calibration was achieved using $2 \mathrm{ml}$ air-saturated $0 \cdot 1 \mathrm{M}$ sodium phosphate buffer $(\mathrm{pH} 7 \cdot 0)$, assumed to contain $220 \mathrm{nmol}$ oxygen $\mathrm{ml}^{-1}$ at $37^{\circ} \mathrm{C}$, followed by a few grains of sodium dithionite to remove all dissolved oxygen. For oxygen uptake measurements, cell membranes (about $1.3 \mathrm{mg}$ protein) were added and the oxygen uptake was followed for $5 \mathrm{~min}$ or until a linear rate of oxygen consumption was attained. Substrate was added with a Hamilton microsyringe (to give final concentrations of $10 \mathrm{mM}$ ), and the rate of oxygen consumption was recorded. Where indicated, Q-1 $(80 \mu \mathrm{M}$ final concentration) was added a few minutes after adding substrate.

Recording of electronic absorbance spectra. Reduced minus oxidized difference spectra were obtained at room temperature using a Johnson Foundation SDB-3 dual-wavelength scanning spectrophotometer, similar to that described by Williams \& Poole (1987). The pathlength was $1 \mathrm{~cm}$ and the reference wavelength was $575 \mathrm{~nm}$. Cells were washed and resuspended in $0 \cdot 1 \mathrm{M}$ phosphate buffer. A few grains of sodium dithionite were added to reduce a sample, and ammonium persulphate (a 
few grains) was used with shaking to oxidize a sample. A baseline was recorded as the difference of two successive scans of an oxidized sample. The data were stored in the instrument memory, and reduced minus oxidized spectra were directly plotted, by subtraction of the stored spectrum.

Photodissociation spectra exploit the light sensitivity of carbonmonoxy compounds of haem proteins. Membranes were resuspended in $0.1 \mathrm{M}$ potassium phosphate buffer (pH 7.0). The sample was transferred to a specially constructed metal/Perspex cuvette and ethylene glycol (to a final concentration of $30 \%, \mathrm{v} / \mathrm{v}$ ) was added as antifreeze. The sample was reduced with either dithionite or NADH $(10 \mathrm{mM}$ final concentration, $1 \mathrm{~h}$ at $37^{\circ} \mathrm{C}$ ). The reduced sample was bubbled with $\mathrm{CO}$ and then cooled in an ethanol/solid $\mathrm{CO}_{2}$ bath at $-78{ }^{\circ} \mathrm{C}$ for at least $5 \mathrm{~min}$ in the dark before further equilibration at $-100^{\circ} \mathrm{C}$ in the sample compartment of the dual-wavelength spectrophotometer. Electron-transfer events following reaction of oxidases with oxygen were studied by photolysing the $\mathrm{CO}$ complex of the reduced oxidase in the presence of oxygen. After reduction with $\mathrm{NADH}$ and $\mathrm{CO}$ treatment as above, the cuvette was transferred to an ethanol/solid $\mathrm{CO}_{2}$ bath at $-23{ }^{\circ} \mathrm{C}$ and, after equilibration, vigorously stirred in the dark with a close-fitting coiled wire (20-30 vertical strokes) to introduce oxygen to about $300 \mu \mathrm{M}$ (Chance et al., 1975a). The sample was then immediately trapped at $-78^{\circ} \mathrm{C}$, then transferred to the sample compartment of the spectrophotometer. The temperature was controlled by a flow of cold $\mathrm{N}_{2}$ gas, cooled by passing through a coiled copper tube immersed in liquid $\mathrm{N}_{2}$ and then through a small heater providing a temperature in the cuvette holder of $-100^{\circ} \mathrm{C} \pm 1{ }^{\circ} \mathrm{C}$. The sample (reduced $+\mathrm{CO}$, oxygen in frozen solution) was scanned twice generating a reduced $+\mathrm{CO}$ minus reduced + $\mathrm{CO}$ baseline and then photolysed by light from a $200 \mathrm{~W}$ slide projector for $1 \mathrm{~min}$. The light source was placed $0.6 \mathrm{~m}$ from the afferent limb of a bifurcated light guide that transmitted the actinic light to the temperature-regulated, insulated cuvette holder. Focusing of the source to a spot $6 \mathrm{~mm}$ diameter on the light guide was done with a lens of focal length $100 \mathrm{~mm}$. The spectrum of the difference between the photolysed sample and the reduced + $\mathrm{CO}$ sample was computed and plotted.

Multiple-wavelength recordings of cytochrome oxidoreduction kinetics. A spectrophotometer (University of Pennsylvania School of Medicine Research Instrumentation Shop, Room 79E John Morgan, Philadelphia, PA 19104, USA), constructed as described by Chance et al. (1975b), was used. In the dual-wavelength mode (for details see D'mello et al., 1994), interference filters (Omega Optical) transmitting maximally at $560 \mathrm{~nm}$ and $575 \mathrm{~nm}$ provided light appropriate for monitoring absorbance of the $\alpha$-band of cytochromes $b$ and the nearest isosbestic point, respectively. The filters were mounted in an air-driven turbine disc, rotating about an axis parallel to the light beam from a Nikon $50 \mathrm{~W}$ halogen source. The speed of the turbine (driven from a filtered, compressed air supply) provided a chopping frequency of $100 \mathrm{~Hz}$. The photo-multiplier was a Thorn-EMI QL-30-RF1 in the 'endon' configuration. The suspension of cell membranes $(2 \mathrm{ml})$ in buffer (0.05 M PIPES, $8 \mathrm{mM}$ magnesium acetate, $\mathrm{pH} 7.0$ ) was stirred (see below) continuously for $5 \mathrm{~min}$ in a $4 \mathrm{ml}$ open cuvette ( $1 \mathrm{~cm}$ path length) before adding substrate $(0 \cdot 1 \mathrm{M}$ $\mathrm{NADH}, 100 \mu \mathrm{l} ; 1 \mathrm{M}$ sodium D-lactate, $20 \mu \mathrm{l} ; 1 \mathrm{M}$ sodium succinate, $20 \mu \mathrm{l} ; 1 \mathrm{M}$ glycerol 3-phosphate, $20 \mu \mathrm{l} ; 1 \mathrm{M}$ sodium formate, $20 \mu \mathrm{l}$ ). The steady-state reduction level of cytochrome $(s) b$ was continuously monitored by plotting $\Delta A_{560-575}$. In Fig. 4(a-e) (see Results), the data are shown as discrete points measured at time intervals from the continuous chart recordings, of which Fig. $4(\mathrm{f})$ is an example. Throughout the period of measurement, the sample was continuously aerated by stirring with a magnetic 'flea' driven from below by a rotating button magnet mounted on a DC motor, controlled by a constant speed power supply. A mu-metal magnetic shield was located between the stirrer/cuvette assembly and the photomultiplier to guard it from electromagnetic interference generated by the rotating magnet and motor $(\mathrm{N}$. Graham, University of Pennsylvania, unpublished design).

\section{RESULTS}

\section{Construction and verification of a ubiCA knockout mutant strain}

The E. coli ubiCA null mutant was created by homologous recombination. The recombinant plasmid pRKP952 containing the inactivated $u b i C A$ genes was used to transform strain MG1655; transformants were selected on $\mathrm{Km}$ plates at $30^{\circ} \mathrm{C}$; cointegrates were allowed to form by incubating the transformants overnight at $42{ }^{\circ} \mathrm{C}$ on LB plates containing both $\mathrm{Km}$ and $\mathrm{Cm}$. Cells from eight colonies were pooled and transferred to rich liquid medium (LGN/Km/Cm) and three growth cycles were performed anaerobically at $30^{\circ} \mathrm{C}$, the permissive temperature for replication of the plasmid. A final growth cycle was performed in LGN at $42{ }^{\circ} \mathrm{C}$ to dilute out the resolved plasmids. Following a screen of $>1000 \mathrm{Km}^{\mathrm{R}}$ colonies, one $\mathrm{Km}^{\mathrm{R}} \mathrm{Cm}^{\mathrm{S}}$ isolate was retained as RKP4152.

The genetic construction in the $u b i C A:: \mathrm{Km}^{\mathrm{R}}$ strain was verified by PCR analysis. Primers were designed to hybridize at the $5^{\prime}$ side of the $\mathrm{BamHI}$ site in $u b i C$ and at the $3^{\prime}$ side of the BamHI site of $u b i A$ (Fig. 1a). The PCR results are shown in Fig. 1(b). As expected, the DNA from the wild-type strain (lane 2) showed one band equivalent to a fragment of $0.64 \mathrm{~kb}$, whereas the DNA from the cointegrate (lane 3) showed two bands $(0.64$ and $1.3 \mathrm{~kb})$. The presence of the insertion in the mutant is verified in lane 4 , as only the $1.3 \mathrm{~kb}$ band is seen (Fig. 1b). The construction was also verified by Southern blot analysis of EcoRI-restricted genomic DNA from all three strains (results not shown). DNA from the wildtype $\mathrm{Ubi}^{+}$parent did not show any hybridization with the $\mathrm{Km}^{\mathrm{R}}$ gene probe, while both the cointegrate and the mutant showed a single band of $6.3 \mathrm{~kb}$ as expected. When the 'wild-type' PCR product was used as probe, no hybridization was seen with mutant DNA, whereas the wild-type and cointegrate strains gave the expected single bands of $5.7 \mathrm{~kb}$ and $2.2 \mathrm{~kb}$, respectively. Finally, genomic DNA from the three strains was probed with a 517 bp NheI-BclI fragment from that portion of $u b i A$ still anticipated to be present in the mutant construct. A single copy of this fragment was present in both wildtype and mutant strains, whereas two copies were present in the cointegrate (data not shown).

\section{Growth phenotype of the ubicA mutant}

In contrast to both wild-type and cointegrate strains, the $u b i$ mutant was unable to grow aerobically on succinate minimal medium plates. However, the $u b i$ strain was 

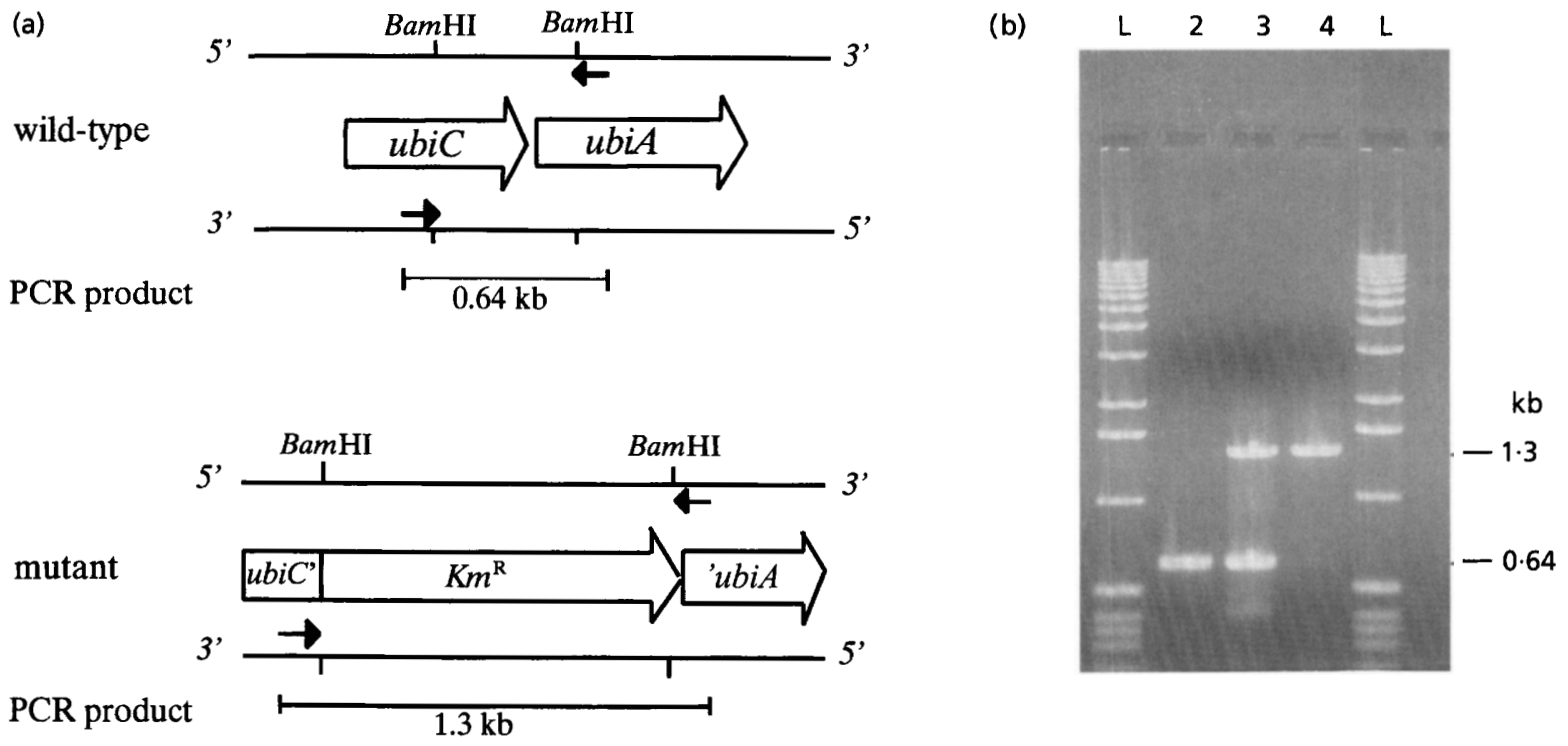

Fig. 1. Construction and verification of a ubiCA mutant. (a) Organization of the ubiCA operon in a wild-type strain (top) and the BamHI sites for cloning the $\mathrm{Km}^{\mathrm{R}}$ cartridge. Convergent arrows indicate the positions of the primers used in PCR analysis and the anticipated product size. Below is shown the mutant construct and the anticipated PCR product size. (b) $\mathrm{Gel}$ electrophoresis of the PCR products in wild-type (MG1655, lane 1), cointegrate (RKP4151, lane 2) and the ubiCA knockout mutant (RKP4152, lane 3). Lanes marked $L$ show a $1 \mathrm{~kb}$ ladder (BRL); the sizes of the observed fragments are marked.

Table 2. Growth yields of strains MG1655 (wild-type) and RKP4152 (ubi) grown on similar, limiting concentrations of carbon sources

Growth yields were measured as turbidity, using Klett units. Strains were cultivated in MOPS defined medium supplemented with $0.3 \%$ Casamino acids and in the presence of the indicated carbon sources, either aerobically (no further supplements) or anaerobically with nitrate or fumarate as electron acceptor. Turbidities represent maximum growth yields with $3 \mathrm{mM}$ carbon source, which was experimentally verified as growth-limiting.

\begin{tabular}{|lccc|}
\hline Carbon source & Electron acceptor & \multicolumn{2}{c|}{ Growth yield (Klett units) } \\
\cline { 3 - 4 } & & $\mathbf{M G 1 6 5 5}\left(\boldsymbol{u b i}^{+}\right)$ & RKP4152 (ubiCA $)$ \\
\hline Glucose & $\mathrm{O}_{2}$ & 194 & 23 \\
Glycerol & $\mathrm{O}_{2}$ & 168 & 24 \\
Succinate & $\mathrm{O}_{2}$ & 125 & 0 \\
Glycerol & $\mathrm{NO}_{3}^{-}$ & 40 & 36 \\
Glycerol & Fumarate & 26 & 26 \\
\hline
\end{tabular}

able to grow anaerobically on nitrate/fumarate/glycerol minimal medium plates. We also determined the relative growth yields of the $u b i$ mutant and wild-type strains on limiting concentrations of carbon sources under various conditions of growth in MOPS defined media (Table 2). The concentration of each carbon source used was shown to be limiting by the linear dependence of growth yield on substrate concentration in the $1-5 \mathrm{mM}$ range (not shown). The aerobic growth yield of the $u b i C A$ mutant was reduced to $12-14 \%$ of the yield obtained for the $\mathrm{Ubi}^{+}$strain when limiting glucose or glycerol were provided as sole carbon sources. Q is widely reported to participate in electron transfer to nitrate (for a review see Gennis \& Stewart, 1996) but a ubi mutation was without effect on anaerobic growth yields on nitrate (Table 2). These data confirm the findings of Cox et al. (1970) and also demonstrate that fumarate respiration is unaffected by a $u b i$ mutation (Table 2 ).

\section{Oxygen consumption rates}

The total electron flux of the respiratory chain is reflected in the oxygen consumption rate. Membranes from the isogenic strains RKP4152 (ubi) and MG1655 (wild-type) were prepared; the oxygen utilization rates with NADH and lactate as electron donors are shown in 
Table 3. Respiration rates of strains MG1655 (wild-type) and RKP4152 (ubi) and the effects of exogenous ubiquinone

\begin{tabular}{|c|c|c|}
\hline \multirow{2}{*}{$\begin{array}{l}\text { Substrate ( }+ \text { exogenous } \\
\text { quinone) }\end{array}$} & \multicolumn{2}{|c|}{ Oxygen uptake $\left[\mathrm{nmol} \mathrm{O} \min ^{-1}(\mathrm{mg} \text { membrane protein })^{-1}\right.$} \\
\hline & $\operatorname{MG1655}\left(u b i^{+}\right)$ & RKP4152 (ubiCA) \\
\hline $\mathrm{NADH}$ & $34 \cdot 0$ & $6 \cdot 5$ \\
\hline $\mathrm{NADH}+\mathrm{Q}-1$ & $68 \cdot 0$ & $35 \cdot 5$ \\
\hline Lactate & $15 \cdot 0$ & $4 \cdot 3$ \\
\hline Lactate $+80 \mu \mathrm{M}$ Q-1 & $43 \cdot 3$ & $23 \cdot 4$ \\
\hline
\end{tabular}

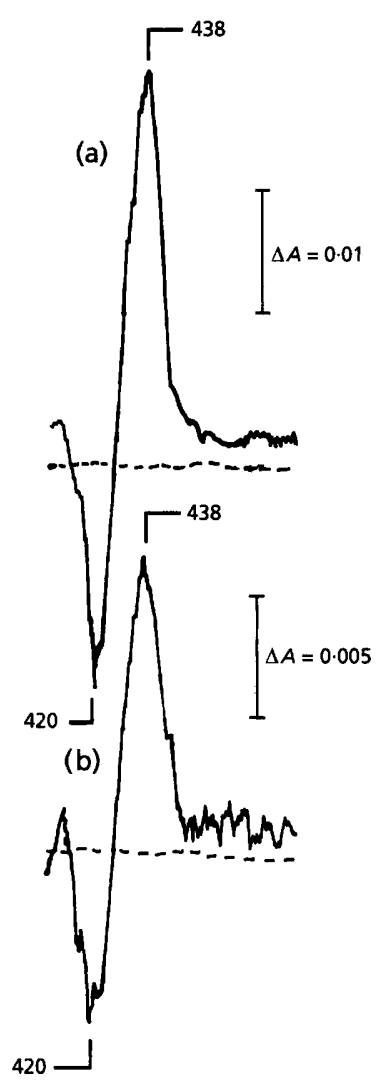

Fig. 2. Photodissociation spectra of dithionite-reduced, COligated membranes from (a) MG1655 $\left(u b i^{+}\right)$and (b) RKP4152 (ubiCA) in the absence of oxygen at $-100^{\circ} \mathrm{C}$. Each spectrum was recorded immediately after photolysis in the dualwavelength scanning mode, with $575 \mathrm{~nm}$ as reference wavelength at $2.86 \mathrm{~nm} \mathrm{~s}^{-1}$ and a spectral band width of $4 \mathrm{~nm}$. The pre-photolysis reduced $+\mathrm{CO}$ minus reduced $+\mathrm{CO}$ baseline is shown as a dashed line. The protein concentrations were $10 \mathrm{mg} \mathrm{ml}^{-1}$ for both (a) and (b).

Table 3. The oxygen uptake rates were clearly much lower in the membranes from the $u b i$ strain and were stimulated by the addition of Q-1. Q deficiency affected $\mathrm{NADH}$ oxidase dramatically, diminishing the rate of oxygen uptake to only $20 \%$ of that in MG1655 membranes. Exogenous $Q$ restored the oxygen uptake of the $u b i$ mutant to wild-type levels and increased the rate of oxygen uptake in MG1655 membranes twofold. No further enhancement was observed by adding Q-1 to higher concentrations. Lactate oxidation was reduced in the $u b i$ membranes to $29 \%$ of wild-type levels. Addition of Q-1 enhanced respiration rates more than fivefold in the mutant membranes but less than threefold in the wild-type membranes.

\section{Spectral characterization}

Reduced minus oxidized difference spectra of membranes prepared from wild-type and $u b i$ cells grown aerobically and anaerobically were recorded at room temperature (not shown). The most distinctive feature of these spectra was the peak at $556 \mathrm{~nm}$ due to cytochrome $b$ reduction. The $u b i C A$ mutation in strain RKP4152 had no significant effect on the cytochrome $b$ content, i.e. both wild-type and $u b i$ mutant membranes from anaerobically grown cells contained cytochromes $b$ at a concentration of $0.18 \mathrm{nmol}(\mathrm{mg} \text { protein })^{-1}$. Cytochrome $d$ was also evident at about $630 \mathrm{~nm}$. The ligand binding haem $\mathrm{O}$ of cytochrome $b o^{\prime}$ makes a small contribution to the bands near $556 \mathrm{~nm}$ and cannot be distinguished spectrally from cytochromes $b$ in such samples.

Since static difference spectra obtained after total reduction and oxidation with dithionite and persulfate, respectively, provide no information on the reactivity of the cytochromes with either oxygen or other electron carriers, we exploited the low-temperature photodissociation behaviour of the terminal oxidases of $E$. coli to measure turnover kinetics. Identification of the oxidase components detectable by this approach is illustrated in Fig. 2, which shows that photolysis, of reduced $\mathrm{CO}$-ligated cytochromes in membranes from either wild-type or $u b i C A$ strains in the absence of oxygen at $-100^{\circ} \mathrm{C}$, revealed a distinctive photodissociation spectrum. In such spectra, peaks above the baseline (reduced $+\mathrm{CO}$ minus reduced $+\mathrm{CO}$ ) arise from the unligated cytochrome formed by photolysis of the $\mathrm{CO}$ adduct, whilst troughs arise from loss of the $\mathrm{CO}$ adduct. Photodissociation spectra of both strains reveal a $438 \mathrm{~nm}$ peak and a $420 \mathrm{~nm}$ trough: these signals are each at wavelengths too high to be attributed to cytochrome o $(415 \mathrm{~nm}$ trough, $430 \mathrm{~nm}$ peak; Poole, 1983). Although cytochrome $b d$ is present in these membranes, as revealed by the presence of distinctive- 


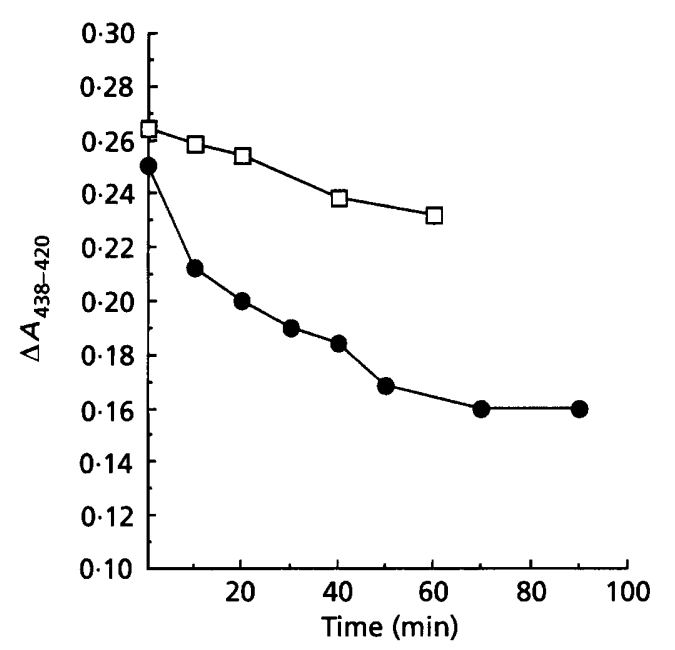

Fig. 3. Absorbance difference changes ( 438 minus $420 \mathrm{~nm}$ ) after photodissociation of cytochrome $b_{595}$ in membranes from MG1655 (ubi $\left.{ }^{+}\right)$( $\square$, protein concentration $10 \mathrm{mg} \mathrm{ml}^{-1}$ ) and RKP4152 (ubiCA) (0, protein concentration $20 \mathrm{mg} \mathrm{ml}^{-1}$ ) in the presence of oxygen at $-100^{\circ} \mathrm{C}$. Spectra were recorded after photolysis of the CO-ligated reduced sample and at the time intervals shown. Successive spectra were recorded in the dualwavelength mode, with $575 \mathrm{~nm}$ as reference wavelength at $2.86 \mathrm{~nm} \mathrm{~s}^{-1}$ and a spectral band width of $4 \mathrm{~nm}$.

$\alpha$-signals in the $630-650 \mathrm{~nm}$ region of reduced minus oxidized difference spectra (results not shown), the Soret signals in Fig. 2 cannot be due to cytochrome $d$, because in the absence of oxygen the recombination of cytochrome $d$ is too fast to be observed at liquid nitrogen temperature (Poole et al., 1982). The Soret signals in Fig. 2 are indistinguishable from those in photodissociation spectra of a cyo mutant of $E$. coli and here, as previously (D'mello et al., 1996), they are attributed to cytochrome $b_{595}$, the high-spin cytochrome $b$ in the cytochrome $b d$ type oxidase complex.

To quantify the turnover of cytochrome $b_{595}$ identifiable in photodissociation spectra, similar experiments were performed after supplementing the CO-ligated membranes with oxygen immediately before freezing under conditions where the oxygen does not displace $\mathrm{CO}$ from the oxidase haem(s). Photolysis of such samples, reduced with $10 \mathrm{mM} \mathrm{NADH}$ at $37^{\circ} \mathrm{C}$ for $1 \mathrm{~h}$, at $-100^{\circ} \mathrm{C}$ (not shown) generated photodissociation spectra for membranes from both strains that were similar in shape to those shown in Fig. 2 (recorded in the absence of oxygen). However, in the case of oxygen-supplemented membranes, the changes in absorbance due to ligand recombination were faster than those in the absence of oxygen, as observed previously (Poole \& Chance, 1981). The kinetics of combination and reaction with ligands may be determined by measuring loss of the spectral signals assigned to the unligated form (i.e. the $438 \mathrm{~nm}$ peak) and/or gain in absorbance due to ligand binding (i.e. the $420 \mathrm{~nm}$ trough). Spectra recorded sequentially after photolysis at intervals of several minutes revealed a decrease in the intensity of the $438 \mathrm{~nm}$ peak, but no change in the intensity of the $420 \mathrm{~nm}$ trough (data not shown), indicating reoxidation of the reduced cytochrome. Fig. 3 shows time-resolved changes in absorbance at these wavelengths $\left(\Delta A_{438-420}\right)$. Observation of the reaction progress over $90 \mathrm{~min}$ showed the reaction to be markedly faster in the case of $\mathrm{Ubi}^{-}$membranes. The simplest explanation of these kinetics is that the faster absorbance changes in $\mathrm{Ubi}^{-}$membranes reflects inhibition of electron flux to the oxidase by $Q$ deficiency with consequently faster loss of the intermediate represented by the spectral changes.

\section{Multiple-wavelength recordings of cytochrome oxidoreduction kinetics}

Previous attempts have been made to identify those electron-transfer reactions in the respiratory chain mediated by $\mathrm{Q}$. The principle of this method is that, in the aerobic steady state (Chance \& Williams, 1956), when both substrate and oxygen are present in excess, the cytochromes become partially reduced, and the amount of this reduction is dependent on the relative activities of dehydrogenases and oxidases. Ubiquinone deficiency equates with 'inhibition' of electron transfer, such that components upstream of $\mathrm{Q}$ become more reduced in $\mathrm{Ubi}^{-}$membranes, whereas components downstream become more oxidized due to continued electron transfer to oxygen, without replacement of electrons normally donated by Q. Several dual-wavelength and split-beam spectrophotometric experiments involving time-sampling after substrate addition have given conflicting results (see Discussion). In the present work, we exploited the ability to record continuously the absorbance changes in cytochrome(s) $b$ in turbid suspensions, without the need for sampling or interruption to the stirring and aeration of the sample.

The levels of reduction of cytochrome(s) $b$ in aerobic steady states in membranes prepared from aerobically and anaerobically grown cells are shown in Fig. 4. In all cases, levels of cytochrome reduction are presented as a percentage of that attained with sodium dithionite. Membranes were clearly not fully reduced, showing that the sample did not become anaerobic during spectrophotometric observation. When NADH was added to membranes from aerobically grown $\mathrm{Ubi}^{+}$cells (Fig. 4a), rapid reduction of cytochrome $b$ was observed, reaching a level of about $35 \%$ of that attained with dithionite in $1 \mathrm{~min}$. In membranes from the $u b i C A$ mutant, reduction was slower, as anticipated for a carrier downstream of Q. However, on prolonged observation, the level of cytochrome $b$ reduction attained exceeded that in the $\mathrm{Ubi}^{+}$membranes. When lactate was provided as substrate (Fig. 4b), initial rates of cytochrome $b$ reduction were similar, but again the level of cytochrome $b$ reduction observed in the $\mathrm{Ubi}^{-}$membranes after $20 \mathrm{~min}$ exceeded that in $\mathrm{Ubi}^{+}$membranes. Similar results were obtained with succinate (not shown). In membranes from anaerobically grown cells, which could be grown to higher yields, cytochrome $b$ reduction exceeded control levels ( $\mathrm{Ubi}^{+}$membranes) in experiments in which NADH (Fig. 4c) or lactate (Fig. 4d) were provided, reaching about $50 \%$ of the level attained with dithionite 

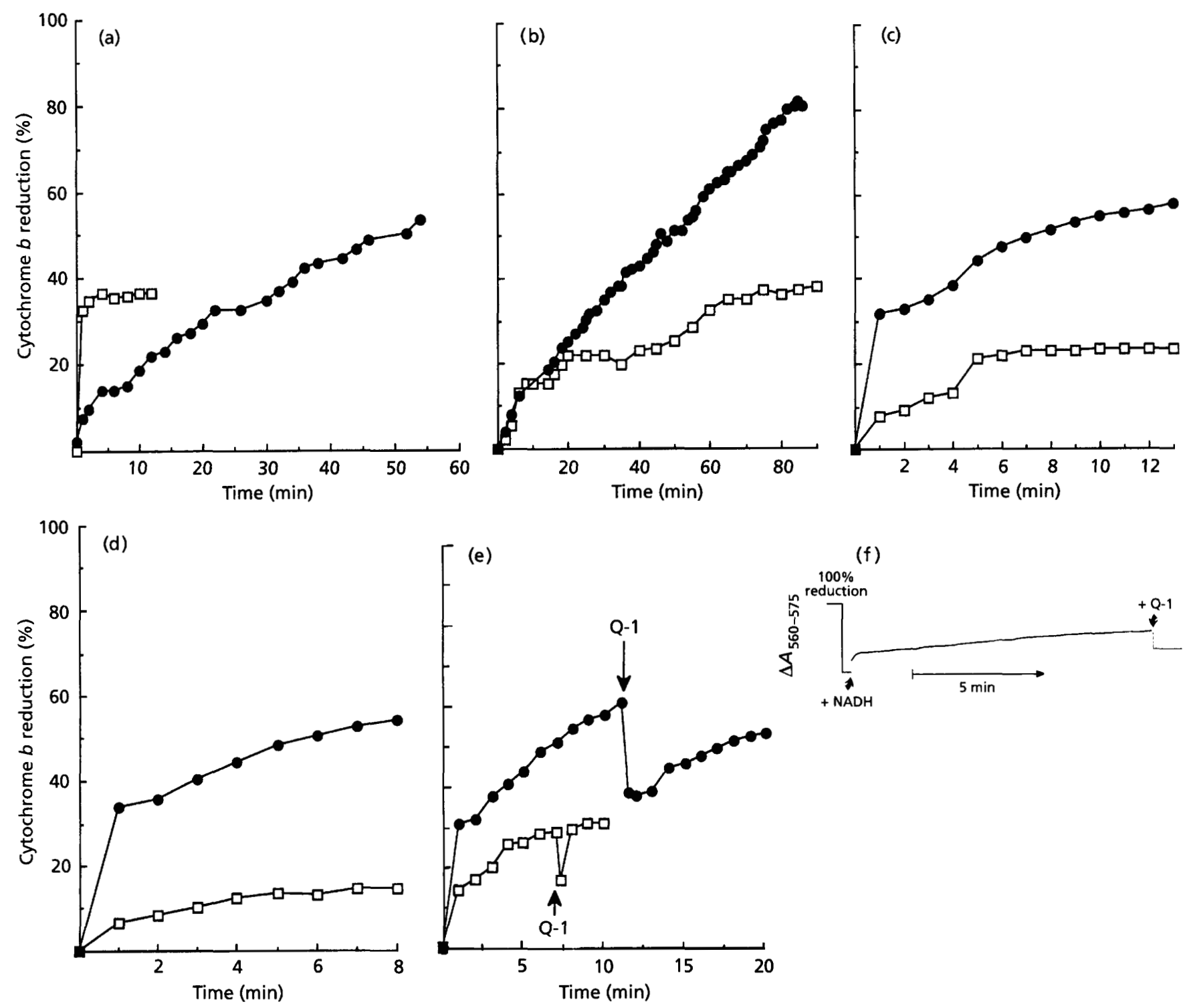

Fig. 4. Kinetics of cytochrome $b$ reduction in membranes from MG1655 (ubi $i^{+}$( $\square$ ) and RKP4152 (ubiCA) (O) as measured by continuous dual-wavelength spectrophotometry of a constantly stirred suspension oxidizing the following substrates: $\operatorname{NADH}(a, c, e)$; lactate (b, d). Traces in (a) and (b) were obtained with membranes from aerobically grown cells; traces in (c), (d) and (e) were obtained with membranes from anaerobically grown cells. In (e), Q-1 was added to membranes from both $u b i$ and wild-type strains at the points indicated by the arrows. Trace ( $f$ ) shows a portion of the continuous $\Delta A$ recording from the multi-wavelength spectrophotometer used to obtain the data points in (e) and $100 \%$ reduction corresponds to $\Delta A_{560-575}$ of about 0.3 . The protein concentrations ( $\mathrm{mg} \mathrm{ml}^{-1}$ ) for wild-type and ubi strains, respectively, were: (a) $5 \cdot 7,3 \cdot 2$; (b) $3.3,1.5$; (c) $5 \cdot 0,6.0$; (d) $4.0,13 \cdot 0$; (e) $8.0,14.0$.

in $8 \mathrm{~min}$, compared with $10-20 \%$ reduction in $\mathrm{Ubi}^{+}$ membranes. The same pattern was obtained when formate or glycerol 3-phosphate was used as substrate for anaerobically grown cells. To demonstrate that the enhanced level of reduction in $\mathrm{Ubi}^{-}$membranes was a direct consequence of $\mathrm{Q}$ deficiency, such membranes were supplemented with exogenous Q-1 during the steady state, when cytochrome $b$ reduction had reached about $60 \%$ of the dithionite level (Fig. 4e, f). An immediate decrease in reduction level occurred to a value similar to that measured in control membranes. In contrast, addition of Q-1 to $\mathrm{Ubi}^{+}$membranes elicited no significant change in cytochrome $b$ reduction.

\section{DISCUSSION}

A Q-deficient mutant has been constructed using a gene replacement technique (Hamilton et al., 1989) that obviates the requirement for construction in a strain that is polA, recBC or recD. The method works because the presence of the pSC101 replication origin within the $E$. coli chromosome dramatically reduces the growth rate 
of the cell. Therefore, pSC101 cointegrates grow slowly at $30^{\circ} \mathrm{C}$, whereas cells in which the plasmid has been resolved from the co-integrate demonstrate normal growth rates. The mutant genetic construct produced in this study was verified using both Southern blotting and PCR techniques.

The most striking phenotype of the $u b i C A$ mutant was an inability to grow aerobically on succinate as carbon and energy source, in agreement with previous studies that exploited the ability of quinone analogues to reconstitute electron transfer in membranes from $u b i A$ men $A$ mutants isolated after chemical mutagenesis (Wallace \& Young, 1977). Studies with the deletioninsertion mutant used here demonstrate unequivocally that $Q$ cannot be functionally replaced by menaquinone or demethylmenaquinone in growth on succinate. Growth on glucose or glycerol, although diminished in the $u b i C A$ mutant, was not abolished, presumably as a result of fermentation (in the case of glucose) or use of alternative quinones between dehydrogenases and oxidases. Anaerobic growth yields on nitrate or fumarate as electron acceptors were unaffected in a ubiCA mutant, consistent with earlier literature based on the use of chemically obtained mutants (Gennis \& Stewart, 1996). As reported by Wallace \& Young (1977), oxidation of lactate or NADH by membranes from the $u b i C A$ mutant was restored by addition of a ubiquinone analogue (Q-3 or, in our experiments, Q-1).

Both well-characterized terminal oxidases in E. coli, cytochromes $b o^{\prime}$ and $b d$, are ubiquinol oxidases. Cytochrome $b d$ oxidizes ubiquinol in a lipid bilayer and an inter-helical region on the periplasmic side of the cytoplasmic membrane - the Q-loop - has been proposed as the quinol-binding site. In the cytochrome $b o^{\prime}$ complex, CyoA has been implicated in quinone binding just as subunit II of the mammalian cytochrome $c$ oxidase binds and reduces the electron donor (cytochrome c). In both $E$. coli oxidases, electrons are assumed to be transferred from ubiquinol to a $b$-type cytochrome of the oxidase complex. This work provides direct confirmation of electron transfer from $Q$ to the haem $(\mathrm{s})$ of cytochrome $b d$. The photodissociation spectra shown in Fig. 2 are attributable to cytochrome $b_{595}$ in the cytochrome $b d$ complex (see Results). Following photodissociation of CO, the reduced unligated form of the cytochrome is formed. At the temperatures used here, the reduction level of this cytochrome decreased only slowly in membranes from a $\mathrm{Ubi}^{+}$strain, when observed over a $60 \mathrm{~min}$ period, presumably as a result of electron flux from upstream in the respiratory chain. However, in membranes from a ubiCA mutant, the cytochrome is more rapidly reoxidized as evidenced by the diminishing peak at $438 \mathrm{~nm}$. The observation that the $419 \mathrm{~nm}$ trough, due to the loss of the CO-ligated form, does not approach the baseline confirms that the reactions being observed are oxidoreductions and not religation of $\mathrm{CO}$ (which would cause symmetrical approach of the trough and peak towards the baseline, representing the fully ligated state).
An important finding from studies of cytochrome $b$ reduction levels in respiring membranes is that schemes that implicate only a single pool of $\mathrm{Q}$ between respiratory substrates and oxygen are oversimplified. The present data are in agreement with earlier models for the organization of the E. coli respiratory chain (Cox et al., 1970; Downie \& Cox, 1978) but not the simplified scheme subsequently suggested by Au et al. (1984) and widely illustrated. Downie \& Cox (1978) used a Qdeficient mutant (ubiA351 ubiB409) to determine the sequence of cytochromes and $\mathrm{Q}$ in the aerobic electrontransport chain of E. coli. The amounts of cytochrome(s) reduced during aerobic steady-state conditions were estimated by freeze-trapping samples at timed intervals and recording difference spectra (i.e. part-reduced minus oxidized) on these samples. Two sites for $Q$ involvement were proposed: one between NADH and lactate dehydrogenases and cytochrome $b$, and a second between $b$-type cytochromes and the oxidases. This conclusion was consistent with earlier studies utilizing a $u b i$ mutant susceptible to reversion and in which cytochrome reduction levels were assayed by dual-wavelength spectrophotometry $(560 \mathrm{~nm}$ minus $570 \mathrm{~nm}$ ) after attainment of a steady state during $\mathrm{NADH}$ or lactate oxidation (Cox et al., 1970). In both earlier studies and the present work, cytochrome $b$ reduction was expressed as a percentage of that attained on depletion of oxygen: Cox et al. (1970) reported $23-24 \%$ cytochrome reduction in the $u b i$ mutant and $8-10 \%$ reduction in the $u b i^{+}$strain, whereas Downie \& Cox (1978) reported values of $50-60 \%$ and $5-10 \%$, respectively. Kita \& Anraku (1981) drew similar conclusions based on the effects of the inhibitor piericidin A, a structural analogue of Q. In the aerobic steady state, monitored by freezetrapping samples and difference spectroscopy, the inhibitor caused cytochrome $b_{556}$ to become more reduced than cytochrome $b_{562}$, indicating a role for $Q$ upstream of the latter cytochrome.

Subsequent experiments by $\mathrm{Au}$ et al. (1984) yielded different results. These authors used $u b i$ mutants isolated after chemical mutagenesis into which a cyd mutant allele was introduced to investigate the electron transfer steps prior to cytochrome $b o^{\prime}$ only. The tendency of these strains to revert to $\mathrm{Ubi}^{+}$was noted but 'only those cultures which contained no revertants were used'. In marked contrast to earlier data, cytochrome $b$ reduction, measured at 560 minus $575 \mathrm{~nm}$ at timed intervals on a sample in an oxygen-bubbled cuvette, was lower $(0-<20 \%$ full reduction) than in membranes from $\mathrm{Ubi}^{+}$cells $(5-25 \%)$. These data suggested that $\mathrm{Q}$ exists as a single pool between the dehydrogenases and cytochrome bo'. Au et al. (1984) attributed the discrepancy to the protocols used earlier for maintaining an aerobic steady state and suggested that the samples trapped in the experiments of Downie \& Cox (1978) were oxygen-depleted, leading to artefactually high cytochrome reduction levels.

In the present work, we have attempted to improve the protocols used previously as follows. (1) Most importantly, we have constructed and used a knockout 


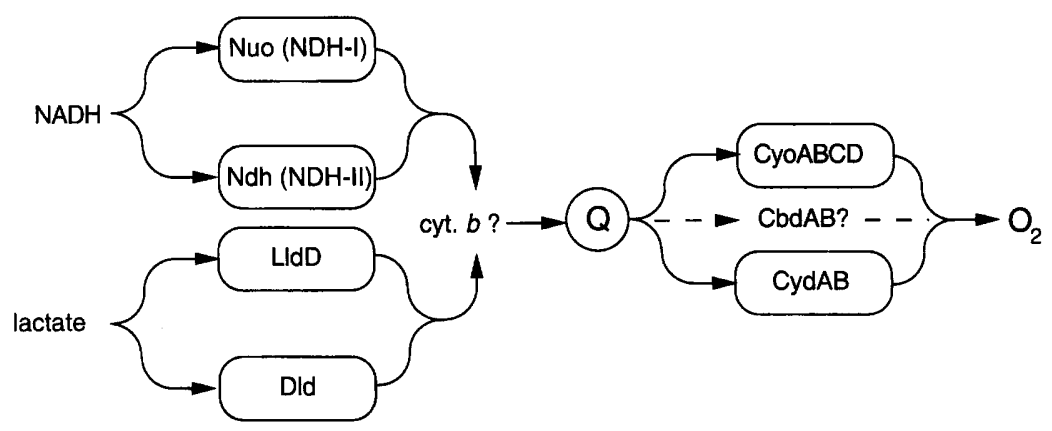

Fig. 5. Schematic diagram of some
components of the aerobic respiratory
chains of $E$. coli. NADH is oxidized by one of
two dehydrogenases; Nuo comprises 14
subunits (not indicated). LldD and Dld are
the dehydrogenases for L- and D-lactate,
respectively. A pool of quinone (circled)
is shown as the immediate reductant for
two terminal oxidases, cytochrome bo'
(CyoABCD) and cytochrome bd (CydAB),
each of which is capable of reducing
oxygen. Components not enclosed are a
putative third oxidase (CbdAB, Sturr et al.,
1996 ) and one or more b-type cytochromes,
suggested to be upstream of Q in the
present work (see Discussion).

mutant having a deletion and insertion at the junction of the $u b i C$ and $u b i A$ genes, which encode the first two steps of the biosynthetic pathway in E. coli. (2) Dualwavelength spectrophotometry was performed continuously without time sampling or attempting to trap redox states. We regard this approach as preferable to sampling, which would allow recording of difference spectra, since the various $b$-type cytochromes have barely distinguishable spectral properties (see Gennis, 1987). In principle, diode-array spectroscopy should allow direct kinetic analysis of multiple wavelengths (see, for example, Poole et al., 1994), but commercially available instruments do not allow satisfactory spectral sensitivity or resolution with turbid samples. (3) Membrane samples were continuously aerated by a custommade magnetic stirring device during the experiment, i.e. throughout the period of spectrophotometric recordings. Au et al. (1984) reported having to stop the bubbling of oxygen through the cuvette when spectrophotometric recordings were made at about $2.5 \mathrm{~min}$ intervals. (4) Reconstitution of oxidase activity in vitro by addition of $\mathrm{Q}$ to membranes from the $u b i$ mutant was used to assign unequivocally the measured redox state to $\mathrm{Q}$ deficiency. This was accompanied by a decrease of the reduction level of cytochrome $b$ to the level in membranes from $\mathrm{Ubi}^{+}$cells.

The present data showing enhanced cytochrome $b$ reduction in membranes from a ubi mutant are not consistent with the simplest schemes that propose a single $Q$ pool upstream of a single location for cytochrome $b$. A number of possible explanations exist. Since both oxidase complexes interact with ubiquinol, yet cytochrome $b$ reduction is increased in $\mathrm{Ubi}^{-}$membranes, a second pool of cytochrome(s) $b$ might occur upstream of a single Q site, as proposed by Downie \& Cox (1978), Kita \& Anraku (1981) and Cox et al. (1970). The identity of this cytochrome is unknown, but Downie \& Cox (1978), on the basis of liquid nitrogen temperature spectroscopy of trapped samples, proposed that both cytochrome $b_{562}$ and $b_{556}$ are upstream of a $\mathrm{Q}$ pool. We have made no attempt to distinguish between the $b$-type cytochromes, favouring continuous monitoring of a single wavelength pair. In the case of reduction by $\mathrm{NADH}$ in membranes from aerobically grown cells, we noted that cytochrome $b$ reduction was slower after adding substrate to $\mathrm{Ubi}^{-}$membranes than in the case of $\mathrm{Ubi}^{+}$membranes (Fig. 4a). A similar observation was made by Downie \& Cox (1978) and attributed to a site for $\mathrm{Q}$ function upstream of cytochrome $b$. Interestingly, the slower reduction of cytochromes $b$ by added NADH (Fig. 4a) was not observed in membranes from anaerobically grown cells (Fig. 4c); indeed, the reduction rates for $\mathrm{Ubi}^{+}$and $\mathrm{Ubi}^{-}$membranes were reversed. This may reflect the differential regulation of two NADH dehydrogenases (NDH) by oxygen. The level of NDH-II is repressed under anaerobic or low-aeration conditions (Green \& Guest, 1994), suggesting that under such conditions (Fig. 4c) NADH oxidation is via NDH-I. One subunit of this 14subunit intrinsic membrane protein, $\mathrm{NuoH}$, is presumed to be a Q-binding subunit (Weidner et al., 1993), although conflicting views exist (Friedrich et al., 1994). The possibility remains that NDH-I donates electrons to a bound $\mathrm{Q}$, thence to cytochrome(s) $b$ of unknown identity (see below), and then to a mobile $\mathrm{Q}$ pool which is the reductant for the terminal oxidases.

These data predict that cytochrome(s) $b$ should be kinetically heterogeneous following reaction of the reduced respiratory chain with oxygen. Indeed, Haddock et al. (1976) resolved two components in stopped-flow experiments: a fast-reacting component (probably comprising haems in the oxidase complexes) and a much more slowly oxidized species (half-time for oxidation about $30 \mathrm{~ms}$ ) which may be the $b$-type cytochrome upstream of Q shown in Fig. 5.

There are several possible candidates for the upstream cytochrome $b$. (1) Cytochrome $b_{556}$ (SdhC, CybA) which is a highly hydrophobic oligomer with a redox potential of $E_{\mathrm{m}}-45 \mathrm{mV}$ has been purified (Kita et al., 1978) and is an anchor polypeptide of the succinate dehydrogenase complex (Murakami et al., 1985). However, this is unlikely to be the sole explanation since we have observed enhanced cytochrome $b$ reduction also with anaerobically grown cells (where succinate dehydrogenase synthesis is repressed) and with a variety of substrates other than succinate. (2) Another candidate is cytochrome $b_{561}$, encoded by cybB (Murakami et al., 1984) and purified and characterized by Murakami et al. 
(1986). It is a low-potential dihaem cytochrome $b\left(E_{\mathrm{m}}\right.$ $+20 \mathrm{mV}$ ) of unknown function but might function upstream of $\mathrm{Q}\left(E_{\mathrm{m}}+113 \mathrm{mV}\right)$. This cytochrome is reducible by $\mathrm{NADH}$ and $\mathrm{D}$-lactate. However, a knockout $c y b$ mutant decreased NADH oxidase activity by $24 \%$ and L-lactate by $18 \%$ only, compared to a wildtype (Yamato et al., 1988). (3) A further, less likely possibility is that a soluble cytochrome such as $b_{562}$ (CybC), which is found in the periplasm (Trower, 1993), might be membrane-associated. Neither of the NADH dehydrogenases or lactate dehydrogenases has been reported to contain haem B (Gennis \& Stewart, 1996).

Another explanation of these results could be the presence of an intramolecular Q tightly bound within a respiratory component receiving electrons from a lowspin haem $b$. Indeed, a novel high-affinity binding site $\left(\mathrm{Q}_{\mathrm{H}}\right)$ distinct from the low-affinity quinol oxidation site $\left(\mathrm{Q}_{\mathrm{L}}\right)$ has been identified in the $E$. coli cytochrome $b o^{\prime}$ type ubiquinol oxidase (Sato-Watanabe et al., 1994). The $\mathrm{Q}_{\mathrm{H}}$ site is located close to the $\mathrm{Q}_{\mathrm{L}}$ site in subunit II and low-spin haem $b_{562}$ in subunit $I$. It is proposed that $\mathrm{Q}_{\mathrm{H}}$ mediates intramolecular electron transfer from $\mathrm{UQH}_{2}$ in the $\mathrm{Q}_{\mathrm{L}}$ site to low-spin haem $b$ as a oneelectron transfer gate, producing a highly stabilized ubisemiquinone radical (Sato-Watanabe et al., 1995). Tight binding of the semiquinone radical confers kinetic and thermodynamic stabilization and prevents destructive side reactions. Using flow-flash and stopped-flow techniques, the reaction of cytochrome $b o^{\prime}$ with oxygen showed either multiphasic kinetics as in cytochrome $c$ oxidase or monophasic kinetics, depending on the isolation procedure - i.e. with or without the presence of a bound ubiquinone molecule (Puustinen et al., 1996). The reduction of dioxygen to water requires four electrons obtained from oxidation of two quinols to quinone. Both cytochrome $b o^{\prime}-$ and $b d$-type terminal oxidases possess only three metal centres each. This suggests that the bound semiquinone, which remains after reduction of all three metal centres, provides the fourth electron (Ingledew et al., 1995). However, the $b d$ type oxidase is the major oxidase identified in our membrane preparations and in this oxidase the presence of a tightly bound ubiquinone has not yet been reported.

Similarly, the UV-sensitive component of purified E. coli nitrate reductase has been identified as MQ-9. Stoichiometric amounts of MQ-9 were found specifically bound to the $\alpha \beta$-dimer and are suggested to participate in intraprotein electron transfer to nitrate (Brito et al., 1995). Likewise, participation of a specifically bound quinone has also been suggested in E. coli fumarate reductase (Westenberg et al., 1993). Clearly, further work is required to unravel the complexities of respiratory electron transport in the multiply branched respiratory chains of this bacterium.

\section{ACKNOWLEDGEMENTS}

We thank BBSRC for a research studentship (to B.S.) and a research grant (to R.K.P.), and the Danish Research Academy for additional financial support to B.S. Helpful advice was provided by Graeme Cox, J. Allan Downie, Frank Gibson,
Norman Graham and Guanghui Wu. J. Purroy constructed plasmid pRKP951.

\section{REFERENCES}

Au, D. C.-T., Green, G. N. \& Gennis, R. B. (1984). Role of quinones in the branch of the Escherichia coli respiratory chain that terminates in cytochrome o. J Bacteriol 157, 122-125.

Brito, F., DeMoss, J. A. \& Dubourdieu, M. (1995). Isolation and identification of menaquinone-9 from purified nitrate reductase of Escherichia coli. J Bacteriol 177, 3728-3735.

Chance, B. \& Williams, G. R. (1956). The respiratory chain and oxidative phosphorylation. In Advances in Enzymology and Related Subjects of Biochemistry, vol. 17, pp. 65-134. Edited by F. F. Nord. New York: Interscience.

Chance, B., Graham, N. \& Legallais, V. (1975a). Low temperature trapping method for cytochrome oxidase oxygen intermediates. Anal Biochem 67, 552-579.

Chance, B., Saronio, C. \& Leigh, J. S. (1975b). Functional intermediates in the reaction of membrane-bound cytochrome oxidase with oxygen. J Biol Chem 250, 9226-9237.

Cox, G. B, Newton, N. A., Gibson, F., Snoswell, A. M. \& Hamilton, J. A. (1970). The function of ubiquinone in Escherichia coli. Biochem J 117, 551-562.

Daniels, D. L., Plunkett, G., Burland, V. \& Blattner, F. R. (1992). Analysis of the Escherichia coli genome: DNA sequence of the region from 84.5 to 86.5 minutes. Science 257, 771-778.

D'mello, R., Hill, S. \& Poole, R. K. (1994). Determination of the oxygen affinities of terminal oxidases in Azotobacter vinelandii using the deoxygenation of oxyleghaemoglobin and oxymyoglobin: cytochrome $b d$ is a low-affinity oxidase. Microbiology 140, 1395-1402.

D'mello, R., Hill, S. \& Poole, R. K. (1996). The cytochrome bd quinol oxidase in Escherichia coli has an extremely high affinity for oxygen and two oxygen-binding haems: implications for regulation of activity in vivo by oxygen inhibition. Microbiology 142, 755-763.

Downie, J. A. \& Cox, G. B. (1978). Sequence of $b$ cytochromes relative to ubiquinone in the electron transport chain of Escherichia coli. J Bacteriol 133, 477-484.

Friedrich, T. \& 10 other authors (1994). Two binding sites of inhibitors in NADH:ubiquinone oxidoreductase (complex I). Relationship of one site with the ubiquinone-binding site of bacterial glucose : ubiquinone oxidoreductase. Eur J Biochem 219, 691-698.

Gennis, R. B. (1987). The cytochromes of Escherichia coli. FEMS Microbiol Rev 46, 387-399.

Gennis, R. B. \& Stewart, V. (1996). Respiration. In Escherichia coli and Salmonella: Cellular and Molecular Biology, 2nd edn, pp. 217-261. Edited by F. C. Neidhardt and others. Washington, DC: American Society for Microbiology.

Gibson, F. (1973). Chemical and genetic studies on the biosynthesis of ubiquinone by Escherichia coli. Biochem Soc Trans 1, 317-326.

Green, J. \& Guest, J. R. (1994). Regulation of transcription at the $n d h$ promoter of Escherichia coli by FNR and novel factors. Mol Microbiol 12, 433-444.

Haddock, B. A., Downie, J. A. \& Garland, P. B. (1976). Kinetic characterization of the membrane-bound cytochromes of Escherichia coli grown under a variety of conditions by using a stopped-flow dual-wavelength spectrophotometer. Biochem $J$ 154, 285-294.

Hamilton, C. M., Aldea, M., Washburn, B. K., Babitzke, P. \& 
Kushner, S. R. (1989). New method for generating deletions and gene replacements in Escherichia coli. J Bacteriol 171, 4617-4622. Hsu, A. Y., Poon, W. W., Shepherd, J. K, Myles, D. C. \& Clarke, C. F. (1996). Complementation of coq3 mutant yeast by mitochondrial targeting of the Escherichia coli UbiG polypeptide: evidence that UbiG catalyzes both $O$-methylation steps in ubiquinone biosynthesis. Biochemistry 35, 9797-9806.

Ingledew, W. J. \& Poole, R. K. (1984). The respiratory chains of Escherichia coli. Microbiol Rev 48, 221-271.

Ingledew, W. J., Ohnishi, T. \& Salerno, J. C. (1995). Studies on a stabilisation of ubisemiquinone by Escherichia coli quinol oxidase, cytochrome bo. Eur J Biochem 227, 903-908.

Kita, K. \& Anraku, Y. (1981). Composition and sequence of $b$ cytochromes in the respiratory chain of aerobically grown Escherichia coli $\mathrm{K}-12$ in the early exponential phase. Biochem Int 2, 105-112.

Kita, K., Yamato, I. \& Anraku, Y. (1978). Purification and properties of cytochrome $b_{556}$ in the respiratory chain of aerobically grown Escherichia coli K12. J Biol Chem 253, 8910-8915.

Lee, P. T., Hsu, A. Y., Ha, H. T. \& Clarke, C. F. (1997). A Cmethyltransferase involved in both ubiquinone and menaquinone biosynthesis: isolation and identification of the Escherichia coli ubiE gene. J Bacteriol 179, 1748-1754.

Maniatis, T., Fritsch, E. F. \& Sambrook, J. (1982). Molecular Cloning: a Laboratory Manual, 2nd edn. Cold Spring Harbor, NY: Cold Spring Harbor Laboratory.

Markwell, M. A. K., Haas, S. M., Bieber, L. L. \& Tolbert, N.E. (1978). A modification of the Lowry procedure to simplify protein determination in membrane and lipoprotein samples. Anal Biochem 87, 206-210.

Meganathan, R. (1996). Biosynthesis of the isoprenoid quinones menaquinone (vitamin $\mathrm{K}_{2}$ ) and ubiquinone (coenzyme $\mathrm{Q}$ ). In Escherichia coli and Salmonella: Cellular and Molecular Biology, 2nd edn, pp. 642-656. Edited by F. C. Neidhardt and others. Washington, DC: American Society for Microbiology.

Murakami, H., Kita, K. \& Anraku, Y. (1984). Cloning of $c y b B$, the gene for cytochrome $b_{561}$ of Escherichia coli. Mol Gen Genet 198, $1-6$.

Murakami, H., Kita, K., Oya, H. \& Anraku, Y. (1985). The Escherichia coli cytochrome $b_{556}$ gene, $c y b A$, is assignable as $s d h C$ in the succinate dehydrogenase gene cluster. FEMS Microbiol Lett 30, 307-311.

Murakami, H., Kita, K. \& Anraku, Y. (1986). Purification and properties of a diheme cytochrome $b_{561}$ of the Escherichia coli respiratory chain. J Biol Chem 261, 548-551.

Nakahigashi, K., Miyamoto, K., Nishimura, K. \& Inokuchi, H. (1992). Isolation and characterization of a light-sensitive mutant of Escherichia coli K-12 with a mutation in a gene that is required for the biosynthesis of ubiquinone. J Bacteriol 174, 7352-7359.

Nonet, M. L., Marvel, C. C. \& Tolan, D. R. (1987). The hisT-purF region of the Escherichia coli K-12 chromosome. Identification of additional genes of the hisT and purF operons. J Biol Chem 262, 12209-12217.

Okada, K., Minehara, M., Zhu, X., Suzuki, K., Nakagawa, T., Matsuda, H. \& Kawamukai, M. (1997). The isp B gene encoding octaprenyl diphosphate synthase is essential for growth of Escherichia coli. J Bacteriol 179, 3058-3060.

Poole, R. K. (1977). The influence of growth substrate and capacity for oxidative phosphorylation on respiratory oscillations in synchronous cultures of Escherichia coli K-12. J Gen Microbiol 99, 369-377.
Poole, R. K. (1983). Bacterial cytochrome oxidases: a structurally and functionally diverse group of electron transfer proteins. Biochim Biopbys Acta 726, 205-243.

Poole, R. K. \& Chance, B. (1981). The reaction of cytochrome $o$ in Escherichia coli $\mathrm{K} 12$ with oxygen. Evidence for a spectrally and kinetically distinct form of cytochrome $o$ in cells from oxygenlimited cultures. J Gen Microbiol 126, 277-287.

Poole, R. K., Sivaram, A., Salmon, I. \& Chance, B. (1982). Photolysis at very low temperature of CO-ligated cytochrome oxidase (cytochrome d) in oxygen-limited Escherichia coli. FEBS Lett 141, 237-241.

Poole, R. K., Williams, H. D., Downie, J. A. \& Gibson, F. (1989). Mutations affecting the cytochrome $d$-containing oxidase complex of Escherichia coli K12: identification and mapping of a fourth locus, cydD. J Gen Microbiol 135, 1865-1874.

Poole, R. K., loannidis, N. \& Yutaka, O. (1994). Reactions of the Escherichia coli flavohaemoglobin (Hmp) with oxygen and reduced nicotinamide adenine dinucleotide: evidence for oxygen switching of flavin oxidoreduction and a mechanism for oxygen sensing. Proc R Soc Lond 255, 251-258.

Puustinen, A., Verkhovsky, M. I., Morgan, J. E., Belevich, N. P. \& Wikström, M. (1996). Reaction of the Escherichia coli quinol oxidase cytochrome $b_{3}$ with dioxygen: the role of a bound ubiquinone molecule. Proc Natl Acad Sci USA 93, 1545-1548.

Sato-Watanabe, M., Mogi, T., Ogura, T., Kitagawa, T., Miyoshi, H., Iwamura, H. \& Anraku, Y. (1994). Identification of a novel quinone-binding site in the cytochrome bo complex from Escherichia coli. J Biol Chem 269, 28908-28912.

Sato-Watanabe, M., Itoh, S., Mogi, T., Matsuura, K., Miyoshi, H. \& Anraku, Y. (1995). Stabilization of a semiquinone radical at the high-affinity quinone-binding site $\left(\mathrm{Q}_{\mathrm{H}}\right)$ of the Escherichia coli botype ubiquinol oxidase. FEBS 374, 265-269.

Spyrou, G., Haggard-Ljungquist, E., Krook, M., Jornvall, H., Nusson, E. \& Reichard, P. (1991). Characterisation of the flavin reductase gene (fre) of Escherichia coli and construction of a plasmid for overproduction of the enzyme. J Bacteriol 173, 3673-3679.

Stewart, V. \& Parales, J. (1988). Identification and expression of genes narL and narX of the nar (nitrate reductase) locus in Escherichia coli K-12. J Bacteriol 170, 1589-1597.

Sturr, M. G., Krulwich, T. A. \& Hicks, D. B. (1996). Purification of a cytochrome $b d$ terminal oxidase encoded by the Escherichia coli app locus from a $\Delta c y o \Delta c y d$ strain complemented by genes from Bacillus firmus OF4. J Bacteriol 176, 1742-1749.

Trower, M. K. (1993). PCR cloning, sequence analysis and expression of the $c y b C$ genes encoding soluble cytochrome $b-562$ from Escherichia coli B strain OP7 and K Strain NM522. Biochim Biophys Acta 1143, 109-111.

Wallace, B J. \& Young, I. G. (1977). Role of quinones in electron transport to oxygen and nitrate in Escherichia coli. Studies with a $u b i A^{-}$men $A^{-}$double quinone mutant. Biochim Biophys Acta 461, 84-100.

Weidner, U., Geier, S., Ptock, A., Friedrich, T., Leif, H. \& Weiss, H. (1993). The gene locus of the proton-translocating NADH: ubiquinone oxideoreductase in Escherichia coli. J Mol Biol 233, 109-122.

Westenberg, D. J., Gunsalus, R. P., Ackrell, B. A. C., Sices, H. \& Cecchini, G. (1993). Escherichia coli fumarate reductase $f r d C$ and frdD mutants. Identification of amino acid residues involved in catalytic activity with quinones. $J$ Biol Chem 268, 815-822.

Williams, H. D. \& Poole, R. K. (1987). The cytochromes of Acetobacter pasteurianus NCIB 6428. Evidence of a role for a 
cytochrome $a_{1}$-like haemoprotein in electron transfer to cytochrome oxidase $d$. J Gen Microbiol 133, 2461-2472.

Wu, G., Williams, H. D., Zamanian, M., Gibson, F. \& Poole, R. K. (1992). Isolation and characterisation of Escherichia coli mutants affected in aerobic respiration: the cloning and nucleotide sequence of ubiG. J Gen Microbiol 138, 2101-2112.

Wu, G., Williams, H. D., Gibson, F. \& Poole, R. K. (1993). Mutants of Escherichia coli affected in respiration: the cloning and nucleotide sequence of $u b i A$, encoding the membrane-bound $p$ hydroxybenzoate:octaprenyltransferase. J Gen Microbiol 139, 1795-1805.
Yamato, I., Nakamura, H., Murakami, H. \& Anraku, Y. (1988). Mapping and disruption of the $c y b B$ gene coding for cytochrome $b_{561}$ in Escherichia coli. FEMS Microbiol Lett 56, 21-28.

Zhu, X., Yuasa, M., Okada, K., Suzuki, K., Nakagawa, T., Kawamukai, M. \& Matsuda, H. (1995). Production of ubiquinone in Escherichia coli by expression of various genes responsible for ubiquinone biosynthesis. J Ferment Bioeng 79, 493-495.

Received 8 August 1997; revised 18 October 1997; accepted 22 October 1997. 